Pacific Journal of Mathematics

WEIGHTED REVERSE WEAK TYPE INEQUALITIES FOR THE 


\section{WEIGHTED REVERSE WEAK TYPE INEQUALITIES FOR THE HARDY-LITTLEWOOD MAXIMAL FUNCTION}

\section{BENJAMIN MUCKENHOUPT}

Kenneth Andersen and Wo-Sang Young recently obtained a sufficient condition and a different necessary condition on a pair of weight functions for which a reverse weak type norm inequality holds for the Hardy-Littlewood maximal function. It is shown here that their necessary condition is also sufficient. The consequences of the sufficiency theorem that they proved are strengthened by use of this result.

1. Introduction. Define the oriented cubes in $R^{n}$ to be those with sides parallel to the coordinate axes, and for a set $E$ in $R^{n}$ let $|E|$ denote the Lebesgue measure of $E$. For $f$ locally integrable on $R^{n}$, define the Hardy-Littlewood maximal function $M f$ by

$$
(M f)(x)=\sup \frac{1}{|Q|} \int_{Q}|f(t)| d t,
$$

where the supremum is taken over all oriented cubes containing $x$. The local sufficiency result proved in [1] for a reverse weak type inequality for the Hardy-Littlewood maximal function is as follows.

THEOREM (1.1). If $U(x)$ and $V(x)$ are nonnegative functions defined on an oriented cube $Q_{0}$ such that

$$
\frac{1}{|Q|} \int_{Q} U(x) d x \geq A \underset{x \in Q}{\operatorname{ess} \sup } V(x)
$$

for all oriented cubes $Q \subset Q_{0}$, then

$$
\int_{Q_{0} \cap\{x:(M f)(x)>\lambda\}} U(x) d x \geq \frac{A 2^{-n}}{\lambda} \int_{\{x:|f(x)|>\lambda\}}|f(x)| V(x) d x
$$

for $f$ supported on $Q_{0}$ and $\lambda \geq\left(1 /\left|Q_{0}\right|\right) \int_{Q_{0}}|f(x)| d x$.

The local necessity result proved in [1] is the following; note that for a cube $Q$ in $R^{n}$ the notation $S Q$ denotes the cube concentric with $Q$ with sides $S$ times as long. 
THEOREM (1.3). If $U(x)$ and $V(x)$ are nonnegative funcíions defined on an oriented cube $Q_{0}$ such that

$$
\text { (1.4) } \int_{Q_{0} \cap\{x:(M f)(x)>\lambda\}} U(x) d x \geq \frac{A}{\lambda} \int_{\{x:|f(x)|>\lambda\}}|f(x)| V(x) d x
$$

for all $f$ which are characteristic functions of measurable sets $E \subset Q_{0}$ and $\lambda \geq\left(1 /\left|Q_{0}\right|\right) \int_{Q_{0}}|f(x)| d x$, then for oriented cubes $Q \subset Q_{0}$,

$$
\frac{1}{|Q|} \int_{2 Q \cap Q_{0}} U(x) d x \geq A 2^{-n} \operatorname{ess~sup}_{x \in Q} V(x) .
$$

If $U(x)$ satisfies the doubling condition $\int_{2 Q \cap Q_{0}} U(x) d x \leq C \int_{Q} U(x) d x$ for oriented $Q \subset Q_{0}$, conditions (1.2) and (1.5) are equivalent. It is easy to see, however, that (1.2) and (1.5) are not equivalent in general by the example $U(x)=V(x)=\chi_{(1 / 2) Q_{0}}(x)$ which satisfies (1.5) for $A=1$ but does not satisfy (1.2) for any finite $A$.

Condition (1.2) resembles the well-known weight condition for $A_{1}$, $(1 /|Q|) \int_{Q} U(x) d x \leq A$ ess $\inf _{x \in Q} U(x)$, introduced on page 214 of [4], and (1.2) looks more "natural" than (1.5). It is, therefore, surprising that (1.5) is in fact a necessary and sufficient condition for the reverse weak type inequality (1.4). The main result of this paper is the following.

THEOREM (1.6). If $U(x)$ and $V(x)$ are nonnegative functions defined on an oriented cube $Q_{0}$ such that

$$
\frac{1}{|Q|} \int_{2 Q \cap Q_{0}} U(x) d x \geq A \underset{x \in Q}{\operatorname{ess} \sup } V(x)
$$

for all oriented cubes $Q \subset Q_{0}$, then

$$
\begin{aligned}
\int_{Q_{0} \cap\{x:(M f)(x)>\lambda\}} U(x) d x & \\
\geq & \frac{A(300 n)^{-n}}{\lambda} \int_{\{x:|f(x)|>\lambda\}}|f(x)| V(x) d x
\end{aligned}
$$

for $f$ supported on $Q_{0}$ and $\lambda \geq \lambda_{0}=\left(1 /\left|Q_{0}\right|\right) \int_{Q_{0}}|f(x)| d x$.

The following global version of Theorem (1.3) is proved in [1] as a corollary of Theorem (1.3).

THEOREM (1.9). If $U(x)$ and $V(x)$ are nonnegative functions defined on $R^{n}$ and

$$
\int_{\{x:(M f)(x)>\lambda\}} U(x) d x \geq \frac{A}{\lambda} \int_{\{x: f(x)>\lambda\}}|f(x)| V(x) d x
$$


for all $f$ which are characteristic functions of measurable sets $E \subset R^{n}$ and all $\lambda>0$, then

$$
\frac{1}{|Q|} \int_{2 Q} U(x) d x \geq A 2^{-n} \underset{x \in Q}{\operatorname{ess} \sup } V(x)
$$

for all oriented cubes $Q \subset R^{n}$.

The sufficiency of this condition will be proved here as the following coroilary of Theorem (1.6). This and Theorem (1.13) generalize results by Stein in [5].

THEOREM (1.10). If $U(x)$ and $V(x)$ are nonnegative functions defined on $R^{n}$ and

$$
\frac{1}{|Q|} \int_{2 Q} U(x) d x \geq A \underset{x \in Q}{\operatorname{ess} \sup } V(x)
$$

for all oriented cubes $Q \subset R^{n}$, then

(1.12) $\int_{\{x:(M f)(x)>\lambda\}} U(x) d x \geq \frac{A(300 n)^{-n}}{\lambda} \int_{\{x:|f(x)|>\lambda\}}|f(x)| V(x) d x$ for all measurable $f$ and $\lambda>0$.

The other results in [1] can be proved with weaker hypotheses by using Theorem (1.6) or Theorem (1.10) in their proofs. These strengthened versions are as follows.

THEOREM (1.13). If $U(x)$ and $V(x)$ are nonnegative functions defined on an oriented cube $Q_{0}$ such that (1.7) holds for all oriented cubes $Q \subset Q_{0}$ with $A>0, f$ is supported on $Q_{0}$ and $\int_{Q_{0}}(M f)(x) U(x) d x<\infty$, then

$$
\int_{Q_{0}}|f(x)|\left[\log ^{+}|f(x)|\right] V(x) d x<\infty .
$$

For the next theorem define $e_{i}$ as the vector in $R^{n}$ with $i$ th entry 1 and all other entries 0. Define $M_{l} f$, the Hardy-Littlewood maximal function in the $i$ th variable by $\left(M_{i} f\right)(x)=\sup _{h \neq 0}(1 / h) \int_{0}^{h}\left|f\left(x+t e_{i}\right)\right| d t$. The following theorem generalizes a result in [2].

THEOREM (1.14). If $U(x)$ is a nonnegative function on $R^{n}, K$ is an integer, $1 \leq K \leq n$, for $h>0,1 \leq i \leq K$ and almost every $x$ in $R^{n}$

$$
\frac{1}{2 h} \int_{-2 h}^{2 h} U\left(x+t e_{i}\right) d t \geq A \underset{|t| \leq h}{\operatorname{ess} \sup } U\left(x+t e_{\imath}\right)
$$


with $A$ independent of $i, x$ and $h$, and $T f(x)=\left(M_{K} \cdots M_{1} f\right)(x)$, then for all $\lambda>0$,

$$
\begin{aligned}
& \int_{\{x: T f(x)>\lambda\}} U(x) d x \\
& \geq \frac{300^{-K} A^{K}}{(K-1) ! \lambda} \int_{\{x:|f(x)|>\lambda\}}|f(x)|\left[\log ^{+}\left(\frac{|f(x)|}{\lambda}\right)\right]^{K-1} U(x) d x .
\end{aligned}
$$

If it is also assumed that $\lim _{|x| \rightarrow \infty} T f(x)=0$ and $\int_{|x|<r} T f(x) U(x) d x<\infty$ for every finite $r$, then

$$
\int_{R^{n}}|f(x)|\left[\log ^{+}|f(x)|\right]^{K} U(x) d x<\infty .
$$

2. Proofs. The proof of Theorem (1.6) is based on the following version of the Whitney covering lemma. As usual, $E^{\circ}$ will denote the interior of the set $E$, and $\chi_{E}$ is the characteristic function of the set $E$.

LeMMA (2.1). Given an open set $G$ in $R^{n}$, its complement $F$ and a closed cube $Q$ such that $G \subset 3 Q$, there exists a sequence $\left\{Q_{j}\right\}$ of closed cubes with sides parallel to those of $Q$ such that

(a) $Q_{j} \subset Q$,

(b) $U Q_{j} \supset G \cap Q^{\circ}$,

(c) $Q_{i}^{\circ} \cap Q_{j}^{\circ}=\varnothing$ if $i \neq j$,

(d) $\operatorname{diam} Q_{j} \leq \operatorname{dist}\left(Q_{j}, F\right) \leq 4 \operatorname{diam} Q_{j}$,

(e) $\sum_{j} \chi_{2 Q_{j}}(x) \leq(33 \sqrt{n})^{n} \chi_{G}(x)$.

The definition of the $Q_{j}$ 's and the proof of (a)-(d) are essentially the proof of Theorem 1, p. 167 of [6]. The principal change is that the initial mesh $\mathscr{M}_{0}$ should be based on $Q$, i.e. $\mathscr{M}_{0}$ consists of $Q$ and translations of $Q$ parallel to its edges by integral multiplies of $S=|Q|^{1 / n}$. The cubes in the mesh $\mathscr{M}_{K}$ then have side length $S 2^{-K}$ and the layers $\Omega_{K}$ are defined by $\Omega_{K}=\left\{x: 2^{1-k} S \sqrt{n}<\operatorname{dist}(x, F) \leq 2^{2-K} S \sqrt{n}\right\}$. Let $A$ be the set of all cubes $q$ for which there is an integer $K$ such that $q \in \mathscr{M}_{K}$ and $q \cap \Omega_{K} \neq \varnothing$. As shown in [6], we have

$$
\operatorname{diam}(q) \leq \operatorname{dist}(q, F) \leq 4 \operatorname{diam}(q)
$$

for $q$ in $A$ and

$$
G=\bigcup_{q \in A} q
$$

Since $G \subset 3 Q$, we have $\operatorname{dist}(q, F) \leq \frac{1}{2} \operatorname{diam}(G) \leq \frac{3}{2} \operatorname{diam}(Q)$ for any cube $q$; this and (2.2) show that $\operatorname{diam}(q) \leq \frac{3}{2} \operatorname{diam}(Q)$ for $q \in A$. Because 
of the choice of $\mathscr{M}_{0}$, we conclude that every $q$ in $A$ is a subset of $Q$ or has interior disjoint from $Q$. Let the $Q_{j}$ be the members of $A$ that are subsets of $Q$ and which are not proper subsets of other members of $A$. Then properties (a) and (c) are immediate, property (d) follows from (2.2) and property (b) follows from (2.3).

The proof of property (e) is an adaptation of the proof of property (4) of the decomposition lemma on pages $15-16$ of [3]. For this proof, fix an $x$ in $\cup_{j \geq 1} 2 Q_{j}$. If $2 Q_{j}$ contains $x$, then $\operatorname{dist}(x, F) \leq \operatorname{dist}\left(x, Q_{j}\right)+$ $\operatorname{diam}\left(Q_{j}\right)+\operatorname{dist}\left(Q_{j}, F\right)$. Since $x \in 2 Q_{j}$, it follows that $\operatorname{dist}\left(x, Q_{j}\right) \leq$ $\left(\frac{1}{2}\right) \operatorname{diam}\left(Q_{j}\right)$, and by (2.2) we have $\operatorname{dist}\left(Q_{j}, F\right) \leq 4 \operatorname{diam}\left(Q_{j}\right)$. Therefore,

$$
\operatorname{dist}(x, F) \leq\left(\frac{11}{2}\right) \operatorname{diam}\left(Q_{J}\right) \text {. }
$$

Similarly, $\operatorname{dist}(x, F) \geq \operatorname{dist}\left(Q_{j}, F\right)-\operatorname{dist}\left(x, Q_{j}\right)$ implies

$$
\operatorname{dist}(x, F) \geq\left(\frac{1}{2}\right) \operatorname{diam}\left(Q_{j}\right) \text {. }
$$

Furthermore, if $y \in Q_{j}$, $\operatorname{dist}(x, y) \leq \operatorname{dist}\left(x, Q_{j}\right)+\operatorname{diam}\left(Q_{j}\right)$. This, the fact that $\operatorname{dist}\left(x, Q_{j}\right) \leq\left(\frac{1}{2}\right) \operatorname{diam}\left(Q_{j}\right)$ and (2.5) show that

$$
\operatorname{dist}(x, y) \leq 3 \operatorname{dist}(x, F) \text {. }
$$

From (2.4), (2.5) and (2.6) it follows that all $Q_{j}$ with $x$ in $2 Q_{j}$ lie in a sphere of radius $3 \operatorname{dist}(x, F)$ about $x$, are disjoint and have diameter greater than or equal to $\left(\frac{2}{11}\right) \operatorname{dist}(x, F)$. Since the sphere of radius $3 \operatorname{dist}(x, F)$ has volume less than $[6 \operatorname{dist}(x, F)]^{n}$, the number of $Q_{j}$ with $x \in 2 Q_{j}$ is bounded by $[6 \operatorname{dist}(x, F)]^{n} /[(2 / 11 \sqrt{n}) \operatorname{dist}(x, F)]^{n}=(33 \sqrt{n})^{n}$. Ths proves (e) for $x$ in $G$. For $x$ not in $G$, property (d) shows that the left side of (e) is 0 . This completes the proof of Lemma (2.1).

To prove Theorem (1.6), fix a $\lambda \geq \lambda_{0}$ and let $G$ be the set where $M f(x)>\lambda$. If $x$ is not in $3 Q_{0}$, then any oriented cube that contains $x$ and intersects $Q_{0}$ has sides with length greater than the sides of $Q_{0}$ and $M f(x)<\left(1 /\left|Q_{0}\right|\right) \int_{Q_{0}}|f(x)| d x=\lambda_{0}$. Therefore, $G \subset 3 Q_{0}$ and we can apply Lemma (2.1) with this $G$ and with $Q$ taken to be $Q_{0}$. By property (e)

$$
\begin{aligned}
\int_{G \cap Q_{0}} U(x) d x & =\int_{Q_{0}} \chi_{G}(x) U(x) d x \\
& \geq(33 \sqrt{n})^{-n} \sum_{j \geq 1} \int_{Q_{0}} \chi_{2 Q_{j}}(x) U(x) d x ;
\end{aligned}
$$

combining this and (1.7) shows that

$$
\int_{G \cap Q_{0}} U(x) d x \geq A(33 \sqrt{n})^{-n} \sum_{j \geq 1}\left|Q_{j}\right| \underset{x \in Q_{j}}{\operatorname{ess} \sup } V(x) .
$$


Now given $j \geq 1$, we have $\operatorname{dist}\left(Q_{j}, F\right) \leq 4 \operatorname{diam}\left(Q_{j}\right)$. Therefore, there is an $x$ in $F$ such that $\left|x-c_{j}\right| \leq\left(\frac{9}{2}\right) \operatorname{diam}\left(Q_{j}\right)$, where $c_{J}$ is the center of $Q_{J}$. Since $9 \sqrt{n} Q$, contains the sphere of radius $\left(\frac{9}{2}\right) \operatorname{diam}\left(Q_{j}\right)$ about $c_{\jmath}$, it follows that $x$ is in $9 \sqrt{n} Q_{J}$, and since $M f(x) \leq \lambda$, we have

$$
\frac{1}{\left|9 \sqrt{n} Q_{j}\right|} \int_{Q_{j}}|f(x)| d x \leq \lambda .
$$

This shows that the right side of (2.7) is bounded below by

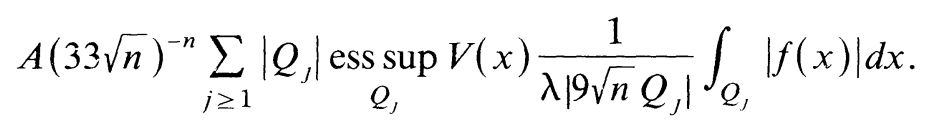

This is bounded below by

$$
\frac{A(300 n)^{-n}}{\lambda} \sum_{j \geq 1} \int_{Q_{j}}|f(x)| V(x) d x .
$$

By property (b) of Lemma (2.1), this is bounded below by

$$
\frac{A(300 n)^{-n}}{\lambda} \int_{G \cap Q_{0}}|f(x)| V(x) d x .
$$

Finally since $M f(x) \geq|f(x)|$ almost everywhere, this is bounded below by the right side of (1.8). This completes the proof of Theorem (1.6).

The proof of Theorem (1.10) is a minor modification of the sufficiency proof of Corollary 1 of [1]. Let $Q_{1}$ be a fixed oriented closed cube. For $t>0$ let $f_{t}(x)=f(x)$ if $|f(x)| \leq t$ and $x \in t Q_{1}, f_{i}(x)=t \operatorname{sgn} f(x)$ if $|f(x)|>t$ and $x \in t Q_{1}$, and $f_{t}(x)=0$ if $x \notin t Q_{1}$. Given $\lambda>0$ and $R$ such that $R>t$ and

$$
\frac{1}{\left|(R-t) Q_{1}\right|} \int_{R^{n}}\left|f_{t}(x)\right| d x \leq \lambda,
$$

define $U_{R}(x)=U(x)$ if $x \in R Q_{1}$ and $U(x)=\infty$ if $x \notin R Q_{1}$. We will apply Theorem (1.6) to $f_{t}$ with $Q_{0}, U$ and $V$ taken respectively as $2 R Q_{1}$, $U_{R}$ and $V$. Hypothesis (1.7) is satisfied if $2 Q \subset R Q_{1}$ by (1.11) while if $2 Q \not \subset R Q_{1}$, hypothesis (1.7) is satisfied because the left side is infinite. Inequality (2.8) implies that $\lambda$ is greater than the required $\lambda_{0}$. Theorem (1.6) then implies that

$$
\begin{aligned}
\int_{2 R Q_{1} \cap\left\{x:\left(M f_{t}\right)(x)>\lambda\right\}} U_{R}(x) d x & \\
\geq & \frac{A(300 n)^{-n}}{\lambda} \int_{\left\{x:\left|f_{t}(x)\right|>\lambda\right\}}\left|f_{t}(x)\right| V(x) d x .
\end{aligned}
$$


Now (2.8) implies that $\left(M f_{t}\right)(x) \leq \lambda$ for $x \notin R Q_{1}$; therefore, (2.9) is equivalent to

$$
\int_{\left\{x:\left(M f_{t}\right)(x)>\lambda\right\}} U(x) d x \geq \frac{A(300 n)^{-n}}{\lambda} \int_{\left\{x:\left|f_{t}(x)\right|>\lambda\right\}}\left|f_{t}(x)\right| V(x) d x .
$$

Now let $t$ approach $\infty$ and use the monotone convergence theorem to complete the proof of Theorem (1.10).

Theorem (1.13) is proved from Theorem (1.6) in the same way that Theorem 2 of [1] is proved from Theorem 1 of [1]. Theorem (1.14) is proved from Theorem (1.10) in the same way that Theorem 3 and Corollary 2 of [1] are proved from Theorem 2 of [1].

\section{REFERENCES}

[1] K. F. Andersen and W.-S. Young, On the reverse weak type inequality for the Hardy maximal function and the weighted classes $L(\log L)^{k}$, Pacific J. Math., 112 (1984), 257-264.

[2] H. A. Favo, E. A. Gatto and C. Gutiérrez, On the strong maximal function and Zygmund's class $L\left(\log ^{+} L\right)^{n}$, Studia Math., 69 (1980), 155-158.

[3] C. Fefferman, Inequalities for strongly singular convolution operators, Acta Math., 124 (1970), 9-36.

[4] B. Muckenhoupt, Weighted norm inequalities for the Hardy maximal function, Trans. Amer. Math. Soc., 165 (1972), 207-226.

[5] E. M. Stein, Note on the class L $\log L$, Studia Math., 32 (1969), 305-310.

[6] Singular Integrals and Differentiability Properties of Functions, Princeton Univ. Press, Princeton, N. J., 1970.

Received October 3, 1983. Research supported in part by N. S. F. Grant MCS 80-03098.

RUTGERS UNIVERSITY

NEW BRUNSWICK, NJ 08903 



\section{PACIFIC JOURNAL OF MATHEMATICS EDITORS}

DONALD BABBITT (Managing Editor)
University of California
Los Angeles, CA 90024
CHARLES R. DEPrIMA
California Institute of Technology
Pasadena, CA 91125
R. FINN
Stanford University
Stanford, CA 94305

\author{
HERMANN FLASCHKa \\ University of Arizona \\ Tucson, AZ 85721 \\ RAMESH A. GANGOLLI \\ University of Washington \\ Seattle, WA 98195 \\ ROBION KIRBY \\ University of California \\ Berkeley, CA 94720 \\ C. C. Moore \\ University of California \\ Berkeley, CA 94720
}

Hugo Rossi

University of Utah

Salt Lake City, UT 84112

H. SAMELSON
Stanford University
Stanford, CA 94305

HAROLD STARK

University of California, San Diego

La Jolla, CA 92093

\section{ASSOCIATE EDITORS}
R. ARens
E. F. BECKENBACH (1906-1982)
B. H. NeUmanN
F. WOLF
K. YOSHIDA

\begin{tabular}{ll}
\multicolumn{2}{c}{ SUPPORTING INSTITUTIONS } \\
UNIVERSITY OF ARIZONA & UNIVERSITY OF OREGON \\
UNIVERSITY OF BRITISH COLUMBIA & UNIVERSITY OF SOUTHERN CALIFORNIA \\
CALIFORNIA INSTITUTE OF TECHNOLOGY & STANFORD UNIVERSITY \\
UNIVERSITY OF CALIFORNIA & UNIVERSITY OF HAWAII \\
MONTANA STATE UNIVERSITY & UNIVERSITY OF TOKYO \\
UNIVERSITY OF NEVADA, RENO & UNIVERSITY OF UTAH \\
NEW MEXICO STATE UNIVERSITY & WASHINGTON STATE UNIVERSITY \\
OREGON STATE UNIVERSITY & UNIVERSITY OF WASHINGTON
\end{tabular}

The Supporting Institutions listed above contribute to the cost of publication of this Journal, but they are not owners or publishers and have no responsibility for its content or policies.

\footnotetext{
Mathematical papers intended for publication in the Pacıfic Journal of Mathematıcs should be in typed form or offset-reproduced (not dittoed), double spaced with large margins. Please do not use built up fractions in the text of the manuscript. However, you may use them in the displayed equations. Underline Greek letters in red, German in green, and script in blue. The first paragraph must be capable of being used separately as a synopsis of the entire paper. In particular it should contain no bibliographic references. Please propose a heading for the odd numbered pages of less than 35 characters. Manuscripts, in triplicate, may be sent to any one of the editors. Please classify according to the scheme of Math. Rev ews, Index to Vol. 39. Supply name and address of author to whom proofs should be sent. All other communications should be addressed to the managing editor, or Elaine Barth, University of California, Los Angeles, California 90024.

There are page-charges associated with articles appearing in the Pacific Journal of Mathematics. These charges are expected to be paid by the author's University, Government Agency or Company. If the author or authors do not have access to such Institutional support these charges are waived. Single authors will receive 50 free reprints; joint authors will receive a total of 100 free reprints. Additional copies may be obtained at cost in multiples of 50 .
}

The Pacific Journal of Mathematics is issued monthly as of January 1966. Regular subscription rate: $\$ 190.00$ a year (5 Vols., 10 issues). Special rate: $\$ 66.00$ a year to individual members of supporting institutions.

Subscriptions, orders for numbers issued in the last three calendar years, and changes of address should be sent to Pacific Journal of Mathematics, P.O. Box 969, Carmel Valley, CA 93924, U.S.A. Old back numbers obtainable from Kraus Periodicals Co., Route 100, Millwood, NY 10546.

The Pacific Journal of Mathematics at P.O. Box 969, Carmel Valley, CA 93924 (ISSN 0030-8730) publishes 5 volumes per year. Application to mail at Second-class postage rates is pending at Carmel Valley, California, and additional mailing offices. Postmaster: Send address changes to Pacific Journal of Mathematics, P.O. Box 969, Carmel Valley, CA 93924.

PUBLISHED BY PACIFIC JOURNAL OF MATHEMATICS, A NON-PROFIT CORPORATION Copyright $\odot 1985$ by Pacific Journal of Mathematics 


\section{Pacific Journal of Mathematics}

\section{Vol. 117, No. 2 \\ February, 1985}

Robert Walter Bagley, Ta-Sun Wu and J. S. Yang, On a class of topological groups more general than SIN groups ............... 209

Bruce Alan Barnes, Algebraic elements of a Banach algebra modulo an ideal ...............................................219

Howard D. Fegan and Peter Gilkey, Invariants of the heat equation .......233

Erica Flapan, Necessary and sufficient conditions for certain homology

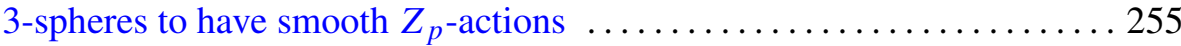

Philip R. Heath, Product formulae for Nielsen numbers of fibre maps . . . . 267

Derbiau Frank Hsu and A. Donald Keedwell, Generalized complete mappings, neofields, sequenceable groups and block designs. II ...... 291

Taqdir Husain, Orthogonal primitive idempotents and Banach algebras

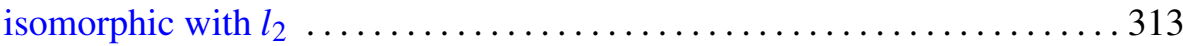

Gary M. Lieberman, Regularized distance and its applications . . . . . . . 329

William W. Menasco, Determining incompressibility of surfaces in alternating knot and link complements ............................ 353

Benjamin Muckenhoupt, Weighted reverse weak type inequalities for the Hardy-Littlewood maximal function $\ldots \ldots \ldots \ldots \ldots \ldots \ldots \ldots \ldots \ldots \ldots \ldots$

John Dacey O'Neill, Direct summands of direct products of slender

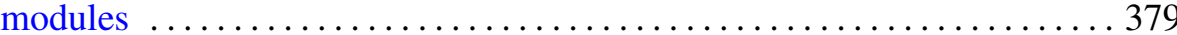

Andreas Rapp, Elimination of Malitz quantifiers in stable theories 387

Francisco José Ruiz, A unified approach to Carleson measures and $A_{p}$ weights

Hanamatagouda Pandappa Sankappanavar, Heyting algebras with dual

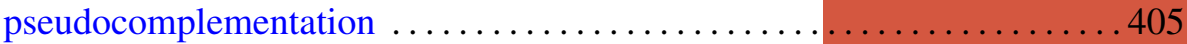

Annette Sinclair, Strong Carleman and strong uniform approximation . . . . 417

Masaaki Suzuki, The generalized Schwarz lemma for the Bergman metric

Brian Thorpe and Ludwig Tomm, Universal approximation by regular

weighted means 